\section{Hur stor andel av de i Sverige inräknade sädgässen har utgjorts av taigasädgäss Anser fabalis fabalis?}

\section{How large proportion of the Bean Geese counted in Sweden was made up of Taiga Bean Geese Anser fabalis fabalis?}

\section{HAKON KAMPE-PERSSON}

Trots att de i Sverige uppträdande sädgässen representerar fem taxa, sex om man även tar med spetsbergsgåsen, har samtliga sädgäss som inräknats vid mittmånadsinventeringarna rapporterats som taigasädgäss Anser fabalis fabalis med visst inslag av andra sädgåstaxa (Nilsson 2000). Att så skett beror på att majoriteten av observatörerna inte gjort någon skillnad på dessa taxa, antingen för att inventeringarna skett vid utsträck från nattlokaler eller för att observatörerna inte ansett sig ha den kunskap som krävs för fältbestämning. Övriga sädgåstaxa har varit tämligen fåtaliga, varför de inte inverkat på de siffror som presenterats för taigasädgåsen (Persson 1990, 1997, Kampe-Persson m.fl. 2007). Ännu opublicerade uppgifter från de senaste säsongerna ifrågasätter dock detta förfaringssätt (Heinicke 2010).

I Sverige startade en ny dabatt om sädgässens rastillhörighet sedan det den 30 april 2008 rapporterats 1100 rossicus tillsammans med 451 fabalis vid Alviksgården i Norrbotten (Rolf G. Gustafsson på Svalan). Vintern 2009/2010 utvidgades debatten geografiskt (Koffijberg \& Hornman 2010). Det finns dock en klar skillnad mellan länderna, ty medan taigasädgäss rapporteras som tundrasädgäss i Nederländerna gäller det omvända i Sverige. Mer bränsle till den svenska debatten presenterades av Thomas Heinicke vid Wetlands Internationals Goose Specialist Groups tolfte möte, vilket hölls i Höllviken i oktober 2009. Enligt de siffror som presenterades under mötet kunde så mycket som 5000-10.000 tundrasädgäss samtidigt uppehålla sig i Sverige. Fältuppgifter från hösten 2009 presenterades som stöd för denna uppfattning. Vid årsskiftet 2009/2010 gjorde sedan Thomas Heinicke en kontroll av sädgässen i nordöstra Skåne, varvid han fann några hundra rossicus bland de där övervintrande taigasädgässen (Leif Nilsson i e-brev). Vid en egen kontroll av samma område i slutet av januari hittades dock endast två rossicus bland 4881 fabalis.

För besvarande av den inledande frågan är uppgifterna på Svalan inte till någon hjälp. Av de knappt 63.000 sädgåsobservationer som fanns i systemet den 1 juli 2009 hade 99,7\% lagts in som sädgås, medan uppdelning på taigasädgås och tundrasädgås endast skett för $0,3 \%$ av observationerna (de Jong 2010). För 2009 och 2010 ser det obetydligt bättre ut. Av 7499 respektive 8224 observationer hade $95,9 \%$ respektive $94,3 \%$ lagts in som sädgås medan uppdelning på taxa skett för $4,1 \%$ respektive $5,7 \%$ av observationerna. Av rastande tundrasädgäss under höst och vinter fanns det för dessa två år tre observationer på mer än hundra individer, två avseende en och samma flock på 120 fåglar i november 2009 och en av en flock på $550 \mathrm{i}$ mitten av september 2010.

Vid mittmånadsinventeringar av gäss i södra halvan av Skåne har sädgässen däremot regelbundet bestämts till taxon alltsedan 1970-talet. Resultaten fram till och med säsongen 1996/1997 har med avseende på förekomsten av rossicus tidigare rapporterats (Persson 1990, 1997), varför här endast de senaste 14 säsongerna redovisas (Tabell 1). Av tabellen framgår tydligt dels att i gruppen övriga sädgåstaxa är det endast rossicus som uppträtt i större antal under inventeringarna och dels att antalet rossicus varierat kraftigt från år till år, framförallt i oktober. Någon tydlig trend kan ej utläsas. Däremot har detta taxon varit talrikast i oktober och fåtaligast i januari. Andelen fabalis har fluktuerat kraftigt i oktober, mellan $17 \%$ och $99 \%$, vilket framförallt beror på det låga antal fabalis som numera förekommer i södra Skåne i oktober. Bortsett från 1998, då ett lågt antal fabalis fanns inom det inventerade området, har procentsiffran varierat betydligt mindre i november (94-100\%). I januari har andelen fabalis genomgående legat på över $99 \%$.

Kunskapen om tundrasädgåsens förekomst i Sverige är ytterst knapphändig, men mycket tyder på att den blivit betydligt talrikare under de senaste 5-10 åren. En komplicerande faktor är att de tundrasädgäss som uppträder i Sverige sannolikt utgörs av fyra vitt skilda grupper.

Grupp I. Den del av populationen som häckar längst $\mathrm{i}$ väst och som regelbundet flyttar mellan Kolahalvön och den tyska östersjökusten (Persson 1997, Heinicke 2004). Sannolikt är det gäss från detta bestånd, vars häckningsområde sträcker sig in i Norge, som setts sträckande vid Segerstad i månadsskiftet september/oktober (Cederroth 1999, Persson 1999, Christian Cederroth på Svalan) och 
Tabell 1. Antal sädgäss funna vid mittmånadsinventeringar genomförda av författaren i södra halvan av Skåne under perioden 1997/1998-2010/2011. För varje inventering anges sädgässen fördelade på taxa samt andelen som utgjordes av fabalis. Hybrider uteslöts. Storväxta individer med extremt lång och smal hals samt extremt lång och smal mörk näbb med endast ett orange-gult band fördes till johanseni.

Number of Bean Geese found at mid-monthly counts carried out by the author in the southern half of Scania during the period 1997/1998-2010/2011. For each count is given the number of Bean Geese divided on taxa and the proportion made up of fabalis. Hybrids were excluded. Large-sized individuals with an extremely long and slender neck and an extremely long and slender dark bill with only a narrow orange-yellow band was counted as johanseni.

\begin{tabular}{|c|c|c|c|c|c|c|}
\hline \multirow{2}{*}{$\begin{array}{l}\text { Inventering } \\
\text { Count }\end{array}$} & \multicolumn{5}{|c|}{ Antal individer Number of individuals } & \multirow{2}{*}{$\begin{array}{r}\% \\
\text { fabalis }\end{array}$} \\
\hline & fabalis & johanseni & middendorfi & rossicus & serrirostris & \\
\hline Okt 1997 & 1657 & & & 11 & & 99,3 \\
\hline Okt 1998 & 202 & & & 1.010 & & 16,7 \\
\hline Okt 1999 & 1437 & & & 1.001 & & 58,9 \\
\hline Okt 2000 & 5 & & & 7 & & 41,7 \\
\hline Okt 2001 & 225 & & & 59 & & 79,2 \\
\hline Okt 2002 & 880 & & & 123 & 30 & 85,2 \\
\hline Okt 2003 & 501 & & & 82 & & 85,9 \\
\hline Okt 2004 & 293 & & & 16 & 6 & 93,0 \\
\hline Okt 2005 & 221 & 7 & & 22 & 6 & 86,3 \\
\hline Okt 2006 & 348 & & & 180 & 2 & 65,7 \\
\hline Okt 2007 & 713 & & & 70 & & 91,1 \\
\hline Okt 2008 & 25 & & & 1 & & 96,2 \\
\hline Okt 2009 & 90 & & & 57 & & 61,2 \\
\hline Okt 2010 & 209 & & & 44 & & 82,6 \\
\hline Nov 1998 & 1265 & & & 521 & & 70,8 \\
\hline Nov 1999 & 6266 & 1 & 4 & 87 & & 98,6 \\
\hline Nov 2001 & 2567 & & & 169 & 6 & 93,6 \\
\hline Nov 2004 & 1769 & & & 30 & & 98,3 \\
\hline Nov 2005 & 7045 & & & 24 & 5 & 99,6 \\
\hline Nov 2006 & 5641 & 2 & 15 & 215 & 5 & 96,0 \\
\hline Nov 2010 & 8365 & & & 5 & & 99,9 \\
\hline Jan 2005 & 17557 & & & 8 & 2 & 99,9 \\
\hline Jan 2006 & 11434 & & 12 & 36 & & 99,6 \\
\hline Jan 2007 & 26813 & 2 & 15 & 164 & & 99,3 \\
\hline Jan 2008 & 19371 & & 1 & 44 & & 99,8 \\
\hline Jan 2009 & 18608 & & & 9 & & 100,0 \\
\hline Jan 2010 & 20741 & & & 32 & & 99,8 \\
\hline Jan 2011 & 8201 & & & 10 & & 99,9 \\
\hline
\end{tabular}

rastande i Norrbotten i månadsskiftet april/maj (Heinicke 2010).

Grupp II. Fåglar som regelbundet sträcker genom landet till och från övervintringslokaler i Danmark, där antalet övervintrande tundrasädgäss ökat kraftigt efter vintern 2003/2004 (Pihl \& Vikstrøm 2006, Stefan Pihl opubl.). Om och i så fall var och när dessa gäss rastar i Sverige är i nuläget okänt.

Grupp III. Gäss som normalt sträcker öster om Östersjön och som endast undantagsvis tar en västligare rutt (Persson 1990). I Sverige ses de ofta tillsammans med bläsgäss, och deras uppträdande i landet stämmer därför ganska väl överens med bläsgåsens (Nilsson 2009).

Grupp IV. Tundrasädgäss som flyttar till Sverige för övervintring. I Skåne noterades en tendens till begynnande övervintring under första halvan av 90 -talet (Persson 1997). Visserligen har rossicus observerats vid varje midvinterinventering de senaste sju åren (Tabell 1), men antalsmässigt har de varit för få för att man skall kunna tala om ett övervintrande bestånd.

Vilka slutsatser kan dras av inventeringarna i Sydskåne? Med tanke på att det totala anta- 
let inräknade sädgäss i Sverige under säsongerna 1997/1998-2008/2009 låg inom intervallet 42.000-68.000 i oktober, 31.000-58.000 i november och 14.000-40.000 i januari (Nilsson 2009), var det endast $\mathrm{i}$ januari som en hög andel återfanns i södra halvan av Skåne. Vid midvinterinventeringarna åren 2005-2009 inräknades i detta område $48-67 \%$ av det totala antalet sädgäss i Sverige. Förutsatt att resultaten för södra Skåne var representativa för hela landet låg antalet rossicus dessa vintrar inom intervallet 16-245 individer. Detta intervall är sannolikt representativt för vintrarna fram till och med 2011, ty det finns inget som tyder på att rossicus skulle ha varit talrikare på andra håll i Sverige än de var i södra halvan av Skåne eller att de skulle ha varit talrikare under perioden 1997/1998-2003/2004 än därefter. Däremot pekar de sydskånska siffrorna på att inslaget av rossicus kan ha varit avsevärt i oktober och november.

Sammanfattningsvis kan konstateras att vi för perioden fram till och med 2010/2011 inte vet hur stor andel av de i oktober och november inräknade sädgässen som utgjorts av fabalis, inslaget av rossicus kan ha varit mycket högt under dessa månader, men att mer än $99 \%$ av totala antalet inräknade sädgäss i januari med stor sannolikhet utgjorts av taigasädgäss.

\section{Referenser}

Cederroth, C. 1999. Segersträcket 1996. Calidris 28(2): 5-16.

Heinicke, T. 2004. Neue Erkenntnisse zum Auftreten der Waldsaatgans in Mecklenburg-Vorpommern. Ornithologische Rundbrief Mecklenburg-Vorpommern 45: 3-18.

Heinicke, T. 2010. Tundrasädgåsen Anser fabalis rossicus under vårflyttningen i norra Sverige - sällsynt gäst eller regelbunden flyttfågel? Ornis Svecica 20: 174-183. (Engelska med svensk sammanfattning).

Jong, A. de 2010. Gör Svalan en sommar? Vår Fågelvärld 69(2): 46-47.

Kampe-Persson, H., Jungbeck, U., Svensson, Å. \& Valfridsson, E. 2007. Rastande och övervintrande gäss i Nordostskåne 1976/77-2006/07. Spoven 31: 155-167.

Koffijberg, K. \& Hornman, M. 2010. Het 'rietganzen-complex'. SOVON-Nieuws 23(1): 18-19.

Nilsson, L. 2000. Förändringar i antal och utbredning hos rastande och övervintrande gåsbestånd i Sverige 1977/781998/99. Ornis Svecica 10: 33-49. (Engelska med svensk sammanfattning).
Nilsson, L. 2009. Internationella sjöfågel- och gås-inventeringarna i Sverige. Arsrapport för 2008/09. 69 sidor. Ekologiska institutionen, Lunds Universitet.

Persson, H. 1990. Förekomsten av tundrasädgås Anser fabalis rossicus i Sverige. Anser 29: 237-244.

Persson, H. 1997. Tundrasädgåsen Anser serrirostris rossicus i Skåne 1974-1996. Anser 36: 179-184.

Persson, H. 1999. Segersträcket 1996 - en kommentar. Calidris 28(4): 28-29.

Pihl, S. \& Vikstrøm, T. 2006. Gæs og svaner i mandtal. Fugle og Natur 26(4): 24-25.

\section{Summary}

This communication addresses one of the questions of the ongoing debate about the occurrence of different Bean Goose taxa in Sweden. The only taxon that besides fabalis was found in any numbers at mid-monthly counts in southernmost Sweden during the last 14 seasons was rossicus. Knowledge about the occurrence of rossicus in Sweden is scanty, but much indicates that this taxon has become more common during the last 5-10 years. A complicating factor is that rossicus occurring in Sweden probably are made up of four different groups: (1) the part of the population breeding furthest to the west and which regularly migrates between the Kola Peninsula and the German Baltic Sea coast, (2) birds that regularly migrates through Sweden to and from wintering grounds in Denmark, (3) birds that normally migrate east of the Baltic Sea and only occasionally follow a more westerly route, and (4) birds that migrate to Sweden for wintering. Reports stored in the database Reportsystem For Birds (Svalan at www.artportalen.se) are of no help to answer the initial question, as observers rarely differentiate between $f a b$ alis and rossicus. For the seasons up to 2010/2011 count data from southernmost Sweden indicate that we don't know the proportions of the counted Bean Geese in Sweden that were made up fabalis in October and November, as the number of rossicus might have been high during these months, but that more than $99 \%$ of the total number in January most likely was made up of fabalis.

Hakon Kampe-Persson, Pulmani, Glūdas pagasts, Jelgavas novads, LV-3040, Lettland. Email: kampepersson@hotmail.com. 